could perhaps be used as well, if necessary.

To have taken five years to reach a consensus that, in an initial $\mathrm{CW}$ treaty, production of all lethal $\mathrm{CW}$ agents should be banned, that lethal CW agents can be defined satisfactorily, and that some, as yet still unspecified, measures should be applied to existing stockpiles, is not exactly impressive progress-particularly when there is still no agreement on how to ensure compliance with such a treaty. Verification remains the major stumbling block to the conclusion of any CW treaty, partial or otherwise.

In recent years, a mass of detailed information on technical methods of verification has been produced by SIPRI, Pugwash and other groups, and presented in the CCD. It has been suggested that therefore all the elements necessary to build an effective $\mathrm{CW}$ treaty are now available, and that all that is needed is a political decision to conclude the treaty. But Ambassador Martin stressed that the USA does not share this view, maintaining that effective solutions to the problems of verification have not yet been found.

A first stage CW treaty would require a verification system capable of providing adequate assurance that $\mathrm{CW}$ agents are not being produced, and that the destruction of stockpiles actually complies, qualitatively and quantitatively, with the provisions of the treaty. There are two broad aspects of verification. First, the methodology. The methods studied include, for example, statistical monitoring of data on the production, transport and use of phosphorus and phosphorus compounds, a technique aimed at detecting possible diversion of phosphorus from civilian industry to military uses; and sophisticated scientific analytical tech- niques capable of detecting organophosphorus compounds in air, water or soil samples (and thus of detecting production of nerve agents), and of monitoring destruction activities, from remote locations. In addition, reconnaissance satellites might be used to observe mothballed production facilities and hence warn of any resumption of activity.

These methods are certainly not foolproof. But, as Martin admitted, $100 \%$ effective verification is not necessarily essential: : what is needed is a system capable of setting the difficulties of evasion high enough to deter treaty violation. These methods, especially when used in combination, could form a useful basis for such a system. And the methods are constantly being developed and refined: SIPRI, unfortunately, seems to have lost interest in chemical disarmament problems, but other groups, such as the Pugwash Chemical Warfare Study Group, are actively engaged in studies on this question.

The other aspect of verification is the implementation of the system. This is a purely political decision, involving an assessment of the adequacy of the degree of assurance that could be provided by the technical verification methods. Martin made the US view quite clear, that in order to obtain adequate assurance of compliance with the provisions of a $\mathrm{CW}$ treaty, there must be provision for supplementing the technical verification methods with on-site inspection of production and destruction facilities, whether on a mandatory or a challenge basis.

On-site inspection has always been a politically sensitive issue, and it is unlikely to be resolved until there is a considerable improvement in international trust and confidence. Of course, in many ways, this is a circular argument: the greater the degree of international confidence, the easier it would be to implement a verification system including on-site inspection, while at the same time the need for extensive verification would decrease. Nevertheless, there is a point at which the degree of international mutual confidence is such that a given level of verification, including on-site inspection, is both perceived to be necessary, and is acceptable, politically, by all sides.

The international chemical disarmament negotiations therefore seem to have reached the stage where, all the technical elements of a verification system being available, the emphasis is on building international confidence. In this context, Ambassador Martin made the valuable suggestion that it "might be useful to consider the feasibility and utility of technical exchange visits to selected chemical production and disposal facilities in different countries". This was an idea that had been emplanted last year within the US administration, and those of other countries, by the Pugwash Chemical Warfare Study Group. It is encouraging that its public endorsement by Ambassador Martin coincided with the Group's latest Workshop, held in London and attended by experts from 11 countries, East, West and nonaligned.

There have been indications, unofficially, that other countries, including the Soviet Union, would respond favourably to this idea. If a programme of visits could be arranged, at which it would be possible to test the methodology of verification in practice, this would represent a significant step forward in the chemical disarmament negotiations.

\title{
ASBESTOS
}

\section{Tiny straws in the wind}

\begin{abstract}
Recent events in Britain have raised anew questions about the true extent of the asbestos health threat. Allan Piper reports on signs that white asbestos may, after all, be just as dangerous as the blue variety, and that the hazards stretch beyond the risk of asbestosis on the factory floor
\end{abstract}

ThAт asbestos is a threat to health is nothing new--the progressive respiratory disease known as asbestosis led to the first asbestos regulations for industry fully 45 years ago. But the latest controversy in Britain has done more than raise questions about the adequacy of the regulations now cover- ing its industrial use; it has also served to publicise the possibility that asbestos poses a threat to the public at large.

For asbestos does not just cause asbestosis. It is also a carcinogen. Minute asbestos fibres, if inspired, can pierce individual cells to cause both cancer of the lung and mesothelioma, a particularly malignant, inoperable cancer which attacks the lining of the pleural cavity. There is also emerging evidence that fibres can migrate across internal membranes: they have been detected in cancerous liver tissue, and may also be able to infiltrate the gastrointestinal tract.

It was only at the end of last month that some of the crucial issues became fully public, when an eight-year-old Department of Health (DHSS) report (together with a revised version) was suddenly made available in the Parliamentary Library following a question in the House of Commons. The report, which was prepared for the DHSS Standing Medical Advisory Committee by a working party it established under the Chairmanship of Sir Richard Doll (then Director of the Medical Research Council's Statistical Unit in London, and now Regius Professor of Medicine at Oxford), clearly states that minimal levels of exposure to asbestos pose a real cancer hazard. According to the report the dangers are not necessarily limited to the naturally fine, blue asbestos, crocidolite, as has hitherto been maintained; they probably extend also to the extensively used white 
asbestos, chrysotile, which is now milled far more finely than in the past-thus posing a far more widespread threat than previously believed (a possibility which the report clearly acknowledges).

In that light, the official view that the dangers of asbestos have remained confined to industry seems complacent. Even regarding the situation within industry, the suggestion that the cancer threat was removed with the exclusion of crocidolite under the updated Asbestos Regulations of 1969 seems worrying now that the DHSS report has identified chrysotile as a possible hazard. Moreover, the report also called for a review of the issues once the 1969 regulations had been in force for five years. That dateline came up last May, but the review is only now getting under way-and not because of the report itself.

How far the authorities should have moved towards enforcing more stringent regulations remains somewhat arguable, however, if only because the broader scientific community can provide few helpful clues which might finally determine the true extent of the dangers of asbestos. A major difficulty arises because there have been few sufficiently long-term studies. Asbestos fibres can only be detected in diseased tissue using electron microscopy, and the complication means that until now they have been sought only in cases known to be associated with asbestos. Consequently, epidemiological studiesinvestigations of disease patterns throughout the population-are lacking. In fact, the situation remains so unclear that different interpretations of such data as exist are leading to a rift within the involved scientific community.

Extremes of opinion about the report's claims are easily found. One Medical Research Council (MRC) scientist told Nature there was "no evidence at all" of any cancer risk to the general population as suggested in the DHSS report. He was also sceptical of the suggestion that chrysotile may be as dangerous as crocidolite. These rejections came even though a colleague at the same unit has published data showing that of 120 mesothelioma cases in a single study, 23-the largest single statistical unit-were attributable to chance exposure to minimal levels of chrysotile.

On the other hand, a research worker in London fully backed the DHSS report, and even went on to suggest that glass fibres and commercially available talcum powder should also be studied as possible carcinogens. These materials could pose a cancer threat similar to that presented by asbestos since it is the size of the fibres, rather than any chemical agent, which is sus-

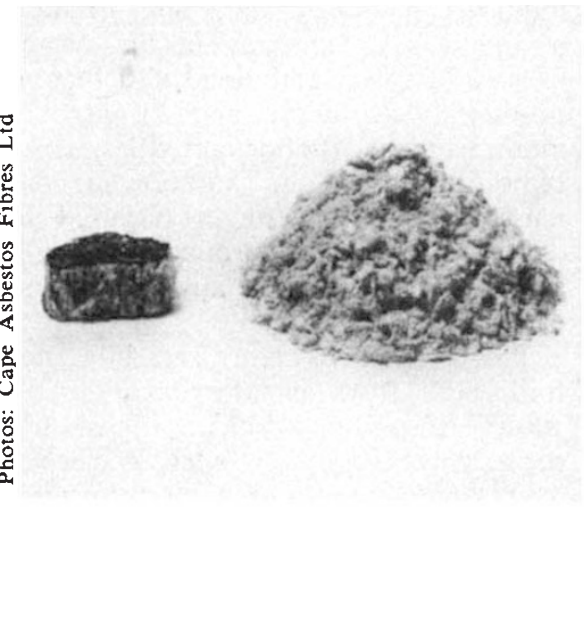

pected of inducing cancer. In fact, a recommendation on minimum fibreglass diameters has already gone out to industry from one MRC unit. Nature was also told that asbestos fibres in the form of anthophyllite have already been detected in studied samples of talcum powder, but a member of the MRC's Pneumoconiosis Unit at Penarth refutes this, claiming that extensive studies on talcs from all over Europe have failed to reveal a single fibre.

The hope is that the ongoing research effort will help resolve the controversy. In Britain work at six MRC units ranges from a major cooperative programme with the Ministry of Defence (into asbestos hazards in naval dockyards), to studies of the aerodynamic properties of fibres. Further MRC laboratory studies of glass fibres are also planned to accompany research already in progress under the sponsorship of the DHSS Health and Safety Executive (HSE), while a major, year-long epidemiological study of all mesothelioma cases should soon be under way at Penarth. In addition, several projects are supported in British universities. On the international front the World Health Organisation's Agency for Research on Cancer announced plans last January for a coordinated epidemiological study on fibre glass workers in Europe; and when its Advisory Committee on Asbestos Cancers meets later this year more research recommendations can be expected.

But while the research efforts continue, the outstanding need for new legislation, and suitable enforcement, remains. The DHSS report underlines the inadequacies of the 1969 regulations, which do not cover the public beyond factory workers and do not recognise the newly defined cancer hazard. Yet no new legislation is planned beyond a marking scheme to cover do-it-yourself asbestos materials. The current review may recommend more, and even the adoption of the

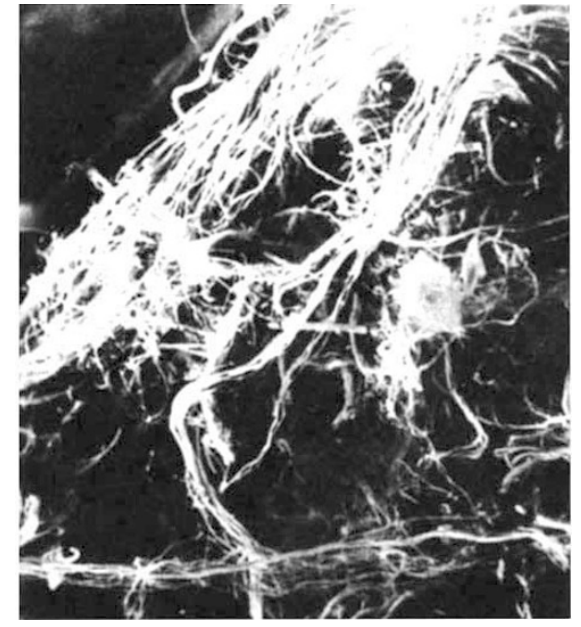

recommendations of the DHSS report would represent a considerable move towards eliminating the general dangers. It would mean the eventual disappearance of crocidolite (which still enters Britain inside manufactured goods), the early introduction of suitable asbestos substitutes, tight controls over the sale, use and disposal of asbestos, and possible checks on general emission levels by the Alkali Inspector.

One difficulty is that the official statistics do not reinforce the case for such action. DHSS figures show only 800 recorded cases of asbestosis, while recorded cases of asbestos cancer and mesothelioma are negligible. But whether the numbers mean very much is questionable on several counts. In the first place, past ignorance of the general danger has ensured that many asbestos cases are attributed to something else (or interpreted as secondary cancers). Industrial settlements out of court provide another distortion. And then there is the hidden factor arising because mesothelioma can take up to 50 years to develop, whereas the asbestos dangers have become significant only during the past 30 or so.

The industry disputes these arguments, and points to a national factory survey by the Health and Safety Executive under existing regulations. Critics regard that move scornfully, particularly after the recent Parliamentary Commissioner's report questioning the vigilance of the Factory Inspectorate at Acre Mill in Yorkshire, the site of an asbestosis tragedy. But they are confronted by a powerful and wellorganised industrial lobby, and equivocal union attitudes.

Meanwhile, many unacknowledged asbestos victims (or their families) go uncompensated. Questions about the dangers of asbestos, and about how to minimise them, have been asked and almost forgotten before. At least now it looks as though the latest resurgence of concern could be sustained until answers are found. 